GABRIEL, A.J.A.; LIMA, M.E.F.; SOUZA, M.A.A.; SOUZA, S.R. Germinação de sementes de alface e de duas ervas invasoras com a aplicação de um novo análogo do estrigol, sintetizado a partir do safrol. Horticultura Brasileira, Brasília, v. 20, n. 4, p. 544-546, dezembro 2002.

\title{
Germinação de sementes de alface e de duas ervas invasoras com a apli- cação de um novo análogo do estrigol, sintetizado a partir do safrol
}

\author{
André José A. Gabriel; Marco Edilson F. de Lima; Marco André A. de Souza; Sonia R. Souza \\ UFRRJ, Rodovia Rio-São Paulo Km 47, 23 851-970 Seropédica-RJ; E-mail: soniabq@ufrrj.br
}

\begin{abstract}
RESUMO
O estrigol é um sesquiterpeno natural que possui elevada atividade como estimulante da germinação, principalmente de sementes de espécies invasoras, pertencentes aos gêneros Striga e Orobanche. Soluções contendo 0,$01 ; 0,1 ; 10$ e $1000 \mathrm{mg} / \mathrm{L}$ de um novo análogo de estrigol, sintetizado a partir de um alilbenzeno natural, o safrol (isolado do óleo de sassafraz), foram aplicadas em sementes de alface e de Ipomoea grandifolia e Bidens pilosa. Observou-se que houve efeito estimulador na germinação das sementes das ervas invasoras, sem afetar a germinação da alface. Os resultados indicam que essa substância apresenta potencial de uso para estimular a germinação de sementes de ervas invasoras, que poderiam ser eliminadas do solo, antes do plantio de hortaliças como a alface.
\end{abstract}

Palavras-chave: Lactuca sativa L., Ipomoea grandifolia (Dammer) O’Don, Bidens pilosa L., estimulante de germinação, óleo de sassafraz.

\begin{abstract}
Germination of lettuce seeds and of two weeds with application of a new strigol analogue, synthesized from safrole

Strigol is a natural sesquiterpene and is a strong stimulant of germination, mainly of weed seeds from the genera Striga and Orobanche. Solutions with concentrations from $0.01 ; 0.1 ; 10$ and 1000 $\mathrm{mg} / \mathrm{l}$ of a new strigol analogue, synthesized from natural safrole (isolated from sassafraz oil) were applied to seeds of lettuce, Ipomoea grandifolia and Bidens pilosa. A stimulating effect in the germination of weed seeds was observed, whereas no effect on lettuce was observed. The results indicate that the new analogue presents potential application as a germination stimulant of weed seeds, which could be eliminated from the soil, before sowing vegetables such as lettuce.
\end{abstract}

Keywords: Lactuca sativa L., Ipomoea grandifolia, Bidens pilosa L., germination stimulant, sassafraz oil.

(Recebido para publicação em 25 de julho de 2000 e aceito em 26 de junho de 2002)

$\mathrm{A}^{\prime}$ lgumas espécies de angiospermas do gênero Striga e Orobanche são exemplos de ervas invasoras que se ligam ao sistema radicular de culturas, e que para germinarem se utilizam de substancias liberadas pelas raízes da planta hospedeira. Estas ervas invasoras, provocam sérios prejuízos às plantações de milho, sorgo, cana-de-açúcar, arroz e mais de 60 diferentes gramíneas em diversas regiões tropicais do planeta (Edwards, 1972).

O estrigol é um sesquiterpeno natural que foi isolado em 1966 de exudados de raízes do algodão (Gossypium hirsutum L.) (Cook et al., 1966) tendo a sua estrutura completamente elucidada em 1972 (Cook et al., 1972). Sua estereoquímica absoluta foi determinada em 1985 (Brooks et al., 1985), sendo o primeiro estimulante de germinação conhecido. A presença desta substância no solo estimula a germinação das sementes das ervas invasoras do gênero Striga e Orobanche. Como esta substância é extremamente ativa, sua utilização em concentrações a $10^{-11} \mathrm{M}$ já é capaz de estimular a germinação das sementes (Cook et al., 1972; Brooks et al.,
1985). Deste modo, este tipo de substância apresenta potencial de uso no controle de ervas invasoras, podendo ser aplicado no solo antes da implantação da cultura no campo.

Vários estudos têm sido feitos na tentativa de se conseguir uma rota sintética economicamente viável para o estrigol, e mesmo para a preparação de análogos. Baseado nos dados descritos na literatura, foi proposta a preparação de um novo análogo, sintetizado à partir do safrol (Lima et al., 2000), que é um alil-benzeno natural, isolado do óleo de sassafraz (Ocotea pretiosa, Benth). Este novo análogo foi obtido como uma mistura de epímeros em C2' (na proporção de 1:1), os quais foram separados por cromatografia líquida de alta eficiência (CLAE), caracterizados separadamente, sendo que a estereoquímica em C2', para cada epímero, ainda não foi atribuída. (Gabriel et al., 2000)

Algumas sementes, como as de alface (Lactuca sativa L.) são fotoblásticas positivas, ou seja, necessitam da presença de luz para germinar. A luz, no caso, pode ser substituída pela aplicação de giberelina, um fitohormônio, que estimula a germina- ção e que é produzido endogenamente, pelo estímulo luminoso (Reynolds \& Thompson, 1973). Se não receberem estes estímulos estas sementes não germinam e são consideradas em dormência. Sementes de outras espécies também podem apresentar esta restrição à germinação. Isto faz com que sementes de ervas invasoras quando enterradas no solo, possam sobreviver por muitos anos, emergindo esporadicamente durante os cultivos sucessivos, quando ficam expostas à luz. A dormência de sementes é um dos fatores responsáveis pelo acúmulo de grandes reservas de sementes viáveis de espécies invasoras no solo. A quebra errática deste fator dificulta seu controle, por estender o período de germinação e emergência de ervas invasoras através da estação de crescimento da cultura (Felipe \& Polo, 1983; Freitas et al., 1990; Jones et al., 1991).

Como as sementes das ervas invasoras podem permanecer no solo e germinar posteriormente ao preparo do terreno para o plantio, vindo a competir por água, nutrientes e luz, a possibilidade de aplicação de uma substância (como o estrigol) que estimule a sua germina- 
ção, possibilitando que elas sejam controladas antes do plantio da cultura, pode representar um importante avanço para reduzir o número de capinas e/ou minimizar o uso de herbicidas que são poluentes e podem prejudicar as plantas cultivadas.

\section{MATERIAL E MÉTODOS}

O novo análogo de estrigol (Figura 1), obtido na forma de uma mistura de epímeros, teve sua atividade avaliada através do estimulo à germinação das ervas invasoras corda-de-viola [Ipomoea grandifolia (Dammer) O’Don.] e picão-preto (Bidens pilosa L.) e da alface (Lactuca sativa $\mathrm{L}$ ).

Foram feitos dois testes de germinação com as sementes de alface e um com as sementes das ervas invasoras.

Dez sementes de alface foram colocadas em placas de Petri com papel de filtro. Soluções contendo $0,1 \mathrm{mg} / \mathrm{L}$ (solução 1) e 10 mg/l de análogo de estrigol em água (solução 2), foram preparadas, no dia do ensaio, a partir de alíquotas retiradas de um estoque com $10 \mathrm{mg}$ do análogo do estrigol em $100 \mathrm{ml}$ de acetona. Alíquotas com quantidades equivalentes de acetona em água foram usadas para o preparo da soluções 'controle 1' e 'controle 2' (como a solução estoque de análogo de estrigol é dissolvida em acetona, estes 'controles' visam avaliar se há efeito deste solvente quando aplicado sem o estrigol). As placas de Petri, contendo as sementes, receberam $10 \mathrm{ml}$ destas soluções, sendo que as testemunhas receberam apenas água. Cada tratamento foi composto por quatro placas (Tabela 1).

As placas permaneceram no escuro por cinco dias sendo a seguir contadas as sementes germinadas. Procedeu-se à análise de variância, e as diferenças entre as médias, quando significativas foram comparadas pelo teste de Tukey a $5 \%$ de probabilidade.

Visando observar se ocorria perda de atividade das soluções de análogo de estrigol com o armazenamento, outro ensaio com sementes de alface foi executado, como descrito anteriormente. Os tratamentos contendo $10 \mathrm{mg} / \mathrm{l}$ (solução 1) e $1000 \mathrm{mg} / \mathrm{l}$ de análogo de estrigol em água (solução 2) foram preparadas
Tabela 1. Germinação de alface em diferentes concentrações (soluções preparadas no dia do ensaio) de análogo do estrigol. Seropédica, UFRRJ, 1999.

\begin{tabular}{lccc}
\hline \multirow{2}{*}{ Tratamentos } & \multicolumn{2}{c}{ Composição das soluções em água } & * Germinação \\
\cline { 2 - 3 } & Acetona (\%) & $\begin{array}{c}\text { Análogo de } \\
\text { estrigol (mg/l) }\end{array}$ & de alface (\%) \\
\hline Testemunha & 0 & 0 & $58,0 \mathrm{ab}$ \\
Controle 1 & 0,0001 & 0 & $44,0 \mathrm{bc}$ \\
Solução 1 & 0,0001 & 0,1 & $72,0 \mathrm{a}$ \\
Controle 2 & 0,01 & 0 & $38,0 \mathrm{c}$ \\
Solução 2 & 0,01 & 10 & $58,0 \mathrm{ab}$ \\
\hline
\end{tabular}

*Letras iguais não diferem significativamente entre si (Teste Tukey, $\mathrm{p}<0,05$ )

Tabela 2. Germinação de alface em diferentes concentrações (soluções armazenadas por sete dias) de análogo do estrigol. Seropédica, UFRRJ, 1999.

\begin{tabular}{|c|c|c|c|}
\hline \multirow[b]{2}{*}{ Tratamentos } & \multicolumn{2}{|c|}{ Composição das soluções em água } & \multirow{2}{*}{$\begin{array}{l}{ }^{*} \text { Germinação } \\
\text { de alface (\%) }\end{array}$} \\
\hline & Acetona (\%) & $\begin{array}{c}\text { Análogo de } \\
\text { estrigol (mg/l) }\end{array}$ & \\
\hline Testemunha & 0 & 0 & $52,5 a b$ \\
\hline Controle 1 & 0,01 & 0 & $42,5 \quad b$ \\
\hline Solução 1 & 0,01 & 10 & $50,0 a b$ \\
\hline Controle 2 & 1 & 0 & $32,5 \quad b$ \\
\hline Solução 2 & 1 & 1000 & $67,5 \mathrm{a}$ \\
\hline
\end{tabular}

*Letras iguais não diferem significativamente entre si (Teste Tukey, $\mathrm{p}<0,05$ )

e armazenadas por sete dias, antes de serem utilizadas (Tabela 2).

No terceiro teste de germinação, as sementes de ervas invasoras, por terem sido coletadas no campo, receberam um pré-tratamento com hipoclorito de sódio a $2 \%$, para profilaxia. Dez sementes de cada espécie foram colocadas em placas de Petri com papel de filtro. As placas receberam $10 \mathrm{ml}$ das soluções, que foram preparadas como descrito nos ensaios com alface. Para o ensaio com ervas invasoras foi escolhida a concentração de análogo do estrigol de $0,1 \mathrm{mg} /$ L por não ter afetado significativamente a germinação da alface (Tabela 1). Para comparação, foi utilizada também a concentração de $0,01 \mathrm{mg}$ de análogo do estrigol/L (Tabela 3). Cada tratamento foi constituído por cinco placas de Petri.

As placas foram colocadas em câmara de germinação. Após três dias as sementes germinadas foram contadas diariamente, até o sétimo dia. Procedeuse à análise de variância e as diferenças entre as médias, quando significativas, foram comparadas pelo teste de Tukey a $5 \%$ de probabilidade.

\section{RESULTADOS E DISCUSSÃO}

A presença do análogo do estrigol, em soluções preparadas no dia do ensaio, não afetou significativamente a germinação da alface, quando comparado com a testemunha que recebeu apenas água (Tabela 1). Entretanto, quando se compara as soluções 1 e 2 com seus respectivos controles (controles 1 e 2 , que receberam acetona), pode-se observar que a presença do análogo do estrigol proporciona percentagem de germinação significativamente maior. Parece que a acetona interfere com o processo de germinação e que a presença do análogo do estrigol na solução suplanta o efeito nocivo da acetona.

Em soluções armazenadas por sete dias observou-se que apenas o tratamento que continha $1000 \mathrm{mg}$ de análogo do estrigol/L (solução 2), apresentou percentagem de germinação da alface significativamente superior ao seu controle (controle 2) (Tabela 2).

O tratamento com $10 \mathrm{mg}$ de análogo de estrigol (solução 1, armazenada 
Tabela 3. Germinação de sementes de corda-de-viola e picão-preto em diferentes concentrações de análogo do estrigol. Seropédica, UFRRJ, 1999

\begin{tabular}{lccccc}
\hline \multirow{2}{*}{ Tratamentos } & \multicolumn{2}{c}{ Composição das soluções em água } & ${ }^{*}$ Germinação de ervas invasoras (\%) \\
\cline { 2 - 5 } & Acetona (\%) & Análogo de estrigol (mg/l) & Corda-de-viola & Picão-preto \\
\hline Testemunha & 0 & 0 & $20,5 \mathrm{c}$ & $60,5 \mathrm{bc}$ \\
Controle 1 & 0,00001 & 0 & $36,5 \mathrm{a}$ & $47,5 \mathrm{~d}$ \\
Solução 1 & 0,00001 & 0,01 & $39,5 \mathrm{a}$ & $70,0 \mathrm{a}$ \\
Controle 2 & 0,0001 & 0 & $34,5 \mathrm{ab}$ & $54,0 \mathrm{~cd}$ \\
Solução 2 & 0,0001 & 0,1 & $24,5 \mathrm{bc}$ & $65,5 \mathrm{ab}$ \\
\hline
\end{tabular}

*Letras iguais na mesma coluna, não diferem significativamente entre si (Teste Tukey, $p<0,05$ )

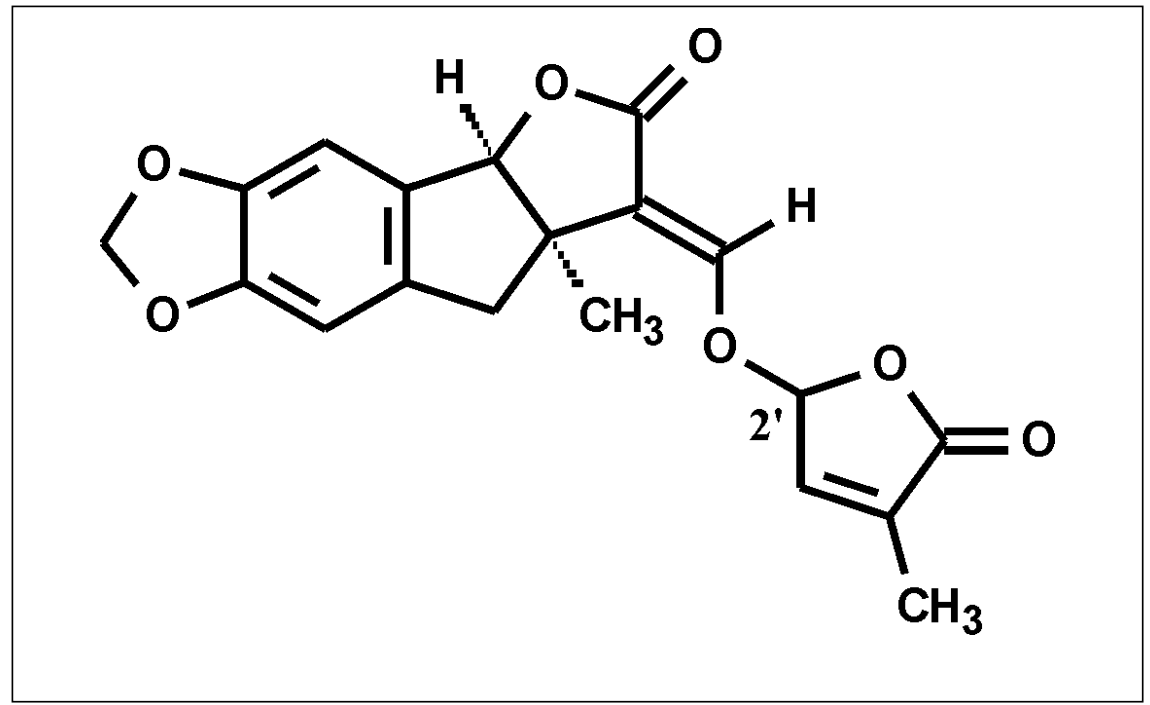

Figura 1. Estrutura química do novo análogo do Estrigol. Seropédica, UFRRJ, 1999.

por sete dias), não afetou significativamente a germinação da alface, em relação ao controle 2 (Tabela 2). Entretanto, quando esta mesma solução é utilizada no mesmo dia de seu preparo (Tabela 1) observa-se efeito contrário, indicando que o armazenamento destas soluções contribuem para a perda de sua atividade.

No ensaio com ervas invasoras (Tabela 3), o tratamento com análogo do estrigol na concentração de $0,01 \mathrm{mg} / \mathrm{L}$ (solução 1) aumentou significativamente a germinação de corda-de-viola e picão-preto, em relação à testemunha, que continha apenas água. Entretanto, apenas para picão-preto, a presença do análogo do estrigol (solução 1) suplantou o efeito nocivo da acetona (controle 1).
Os resultados obtidos indicam que este análogo do estrigol (Figura 1), apresenta atividade como estimulante da germinação de sementes de corda-deviola e de picão-preto, mesmo em baixas concentrações. Assim, apresenta potencial de uso para o manejo de ervas invasoras no cultivo de hortaliças, sem prejudicar a cultura avaliada (alface). Além disto, estes resultados demonstram a aplicabilidade do uso de produtos naturais como precursores de novas substâncias de interesse na área agrícola.

\section{AGRADECIMENTOS}

Os autores agradecem à CAPES pela bolsa de mestrado concedida a A. Gabriel, bem como agradeçem o finan- ciamento dado pelo CNPq (Processo $n$. 520546/95), que possibilitaram a realização deste trabalho.

\section{LITERATURA CITADA}

BROOKS, D.W.; BEVINAKATTI, H.S.; POWELL, D.R. The absolute structure of $(+)-$ Strigol. Journal of Organic Chemistry v. 50, p. 3779-3781, 1985.

COOK, C.E.; WHICHARD, L.P.; TUENER, B.; WALL, M.E. Germination of witchweed (Striga lutea, Lour.): Isolation and properties of a potent stimulant. Science v. 154, p. 1189-1190, 1966. COOK, C.E.; WHICHARD, L.P.; TUENER, B.; WALL, M.E. Germination stimulants II. The structure of Strigol. A potent seed germination stimulant for witchweed (Striga lutea, Lour.). Journal of the American Chemical Society, v. 94, n. 17, p. 6198-6199, 1972.

EDWARDS, W.G.H. Phytochemical EcologyAnnual Proceedings of the Phytochemical Society, n. 8, HARBORNE, J.B., Ed., Academic Press, 1972.

FELIPE, G.M.; POLO, M. Germinação de ervas invasoras: Efeito de luz e escarificação. Revista Brasileira de Botânica, v. 6, n. 1, p. 55-60. 1983. FREITAS, R.R.; CARVALHO, D.A.; ALVARENGA, A.A. Quebra de dormência de sementes de capim-marmelada (Brachiaria Plantaginea, Link Hitch). Revista Brasileira de Fisiologia Vegetal, v. 2, n. 2, p. 31-35, 1990.

JONES JR.; J.B.; WOLF, B.; MILLS, H.A. Plant Analysis Handbook. Micro-Macro Publishing, Inc., 1991.

LIMA, M.E.F; GABRIEL, A.J.A.; CASTRO, R.N. Synthesis of a new Strigol analogue from natural safrole. Journal of the Brazilian Chemical Society, v. 11, n. 4, p. 371-374, 2000.

REYNOLDS, T.; THOMPSON, P.A. Effects of kinetin, giberelins and abscisic acid on the germination of lettuce (Lactuca sativa). Physiologia Plantarum, v. 28, p. 516-522. 1973. 